\title{
OSHA defends leap in carcinogen regulation
}

\section{David Dickson describes a debate over US proposals for dealing with workplace carcinogens}

IT WAS not quite the sell-out that had been predicted. Indeed the polite sparring that characterised the first day of public hearings in Washington last week on the US administration's new proposals for regulating occupational carcinogen was rather an anti-climax.

Yet the presence of ranks of lawyers alone was enough to indicate the wide potential impact-both national and international - of the proposals that have been put forward by the Department of Labor's Occupational Safety and Health Administration (OSHA).

For they are likely to provide the basis for dealing with known or suspected carcinogens across the complete spectrum of government agencies, including the Food and Drug Administration and the Environmental Protection Agency. The chemical industry claims that, as presently conceived, the proposals would add billions of dollars to the costs of production.

What OSHA is proposing is, in effect, a quantum leap in the way that workplace carcinogens are identified, classified and regulated. At present this is done on a case-by-case basis, a thorough but laborious process which partly explains why, in its seven years of existence, OSHA has only developed regulations covering 20 of $1,500-2,000$ suspected carcinogens.

Under the new proposals, ali chemicals shown, under defined conditions, to cause cancer in experimental animals will be classified as carcinogenic. And the steps required to proteot workers will be based not on any risk assessment or cost/benefit analysis, but on an assessment of what protective measures are felt to be economically and technically feasible.

The new proposals have been widely welcomed by many members of the scientific community - as well as trade unions and environmentalist groupsas an appropriate response to the current lack of precise knowledge about the mechanisms or carcinogenicity, and to increasing evidence of the dangers of low levels of exposure which were previously considered safe.

Dr Arthur Upton, director of the National Cancer Institute and one of the scientific witnesses OSHA has asked to provide evidence at the public hearing, said last week that he believed the proposal "has a sound scientific basis and represents a prudent and justifiable approach to the identification and classification of chemical carcinogens". However, the proposals are being strongly contested by private industry, concerned at their potential economic impact.

Industry's attack is being spearheaded by the American Industrial Health Council, an ad hoc group established after the new proposals were announced by Labour Secretary Mr Ray Marshall last autumn. The AlHC now includes among its member 90 companies and 60 national trade associations, and is reputed to have raised over $\$ 1$ million to dispute OSHA's proposals. It has asked for

\section{A summary of the proposals}

\section{All toxic substances shall be classified and subsequently regulated by the Secretary for Labor as follows:}

\section{Classification}

Category I: All toxic substances that meet the definition of "potential occupational carcinogen"* in (i) humans, or (ii) two mammalian test species, or (iii) a single mammalian species, if those results have been replicated in the same species in another experiment, or (iv) a single mammalian species if those results are supported by short-term tests. Also any substance for which the Secretary considers there is sufficient evidence to classify as Category $\mathbf{I}$.

Category II: Any substance defined as a "potential occupational carcinogen" in tests on animals or humans, but for which the evidence is considered only "suggestive". Also, any substance that meets such a definition in an unreplicated cxperiment in a single test species, and any other substance for which the Secretary considers there is sufficient evidence to classify as Category 11.

Category III: Any toxic substance which is used in the US workplace, but which is not classified in Category I or Category II.

Category IV: Foreign toxic substances, ie, those not found in the US workplace.

\section{Regulation}

On classifying a substance as Category I, the Secretary shall immediately issue an Emergency Temporary Standard containing provisional exposure limits. Within 60 days, he or she shall issue a notice of proposed rule-making in order to establish permanent permissible exposure limits. These limits shall be set as low as feasible, and if suitable substitute materials are available, no occupational exposure shall be allowed.

Within 60 days of such classification, the Secretary shall issue a notice of proposed rule-making for permissible exposure limits. These would be (i) present OSHA standards, or (ii) where none exists, an appropriate level based on acute or chronic effects of exposure to the toxic substance other than carcinogenicity, or (iii) lower exposure levels if these are felt necessary. Further research would he stimulated to obtain additional data.

No exposure limits would be suggested, but information would be requested on whether substances should be considered for inclusion in Categories I or II.

No exposure limits would be suggested, unless information was subsequently received that the substance was used in the US workplace.

\footnotetext{
*"Potential occupational carcinogen" means any toxic substance which (1) causes, at any level of exposure or dose, as a result of any oral, respiratory or dermal exposure, or any other exposure which results in the systemic distribution of the substance under consideration in the organism tested, an increased incidence of benign or malignant neoplasms, or a combination thereof, in (i) humans, or (ii) in one or more experimental mammalian species, or (2) in a statistically significant manner decreases the latency period between exposure and onset of neoplasm in (i) humans or (ii) in one or more experimental mammalian species.
} 